\title{
BRUÑA CUEVAS, MANUEL (COORD.) (2008), PHILOLOGIA \\ HISPALENSIS, VOL.XXII: LEXICOGRAFÍA BILINGÜE Y PLURILINGÜE DEL ESPAÑOL (SIGLOS XV-XIX). SEVILLA, UNIVERSIDAD DE SEVILLA, 345 PÁGS.
}

\author{
JuAn Vela Bermejo \\ Universidad de Alicante \\ Juan.Vela@ua.es
}

El volumen XXII de la revista Philologia Hispalensis recoge un total de once estudios lexicográficos sobre los diccionarios, vocabularios, glosarios $\mathrm{u}$ otros repertorios que pusieron en relación directa las voces de la lengua española con las de otras lenguas entre los siglos XV y XIX. De ahí la justificación del título de la obra que refleja estrictamente el futuro contenido de la misma: Lexicografía bilingüe y plurilingüe del español (siglos XV-XIX).

Esta recapitulación se abre con el artículo introductorio "Lexicografía plurilingüe de los siglos XVI y XVII", donde Isabel Acero Durántez ofrece una visión global de los textos lexicográficos plurilingües que incluían el castellano en el intervalo de tiempo especificado. Por una parte, el latín ha dejado de ser la única lengua para establecer relaciones internacionales en esta época; por otra, necesidades de carácter turístico o comercial propiciaron el interés de los usuarios en aprender lenguas modernas. En definitiva, estos hechos dieron lugar a la aparición de textos lexicográficos de carácter plurilingüe que intentaban abarcar las principales lenguas europeas, conformando así obras ordenadas alfabéticamente o por temas, con un recorrido desde diccionarios a diálogos o nomenclaturas y fundamentadas en el trabajo de sus predecesores, desembocando en numerosas ocasiones en un plagio evidente que ha causado problemas en el análisis de las fuentes primarias. A partir de aquí, en el resto del volumen cada autor se centra en el comentario de la producción lexicográfica que ha puesto en contacto directo al castellano con una de las lenguas o grupos de lenguas con las que ha convivido a lo largo de los siglos comentados con anterioridad. 
Manuel Bruña Cuevas trata de una forma detallada en "La producción lexicográfica con el español y el francés durante los siglos XVI a XIX" los rasgos fundamentales de las obras que pusieron en relación las lenguas española y francesa dentro del marco temporal de los siglos indicados, centrando el estudio en producciones lexicográficas bilingües y multilingües tales como el diccionario, el vocabulario técnico o las nomenclaturas temáticas. Por otro lado, en "Breve historia de la lexicografía bilingüe española y alemana hasta el siglo XIX", Ma José Corvo Sánchez plantea una panorámica del trabajo lexicográfico que ha unido al español y al alemán durante los siglos XVII, XVIII y XIX, deteniéndose principalmente en los grandes diccionarios junto a otras recopilaciones menores, pero siempre partiendo de la Nomenclatura españolaalemana (1634) de Juan Ángel de Zumaran como inicio de esta disciplina lexicográfica. En el artículo breve pero con el extenso título "¿Tradición múltiple en la lexicografía vasco-latino románica? Algunas notas sobre el componente fraseológico en diccionarios bilingües y trilingües de los siglos XVI al XVIII: de Nicolás Landuchio (1562) a José María Aizpitarte (c.1785)", Ma Teresa Echenique Elizondo posee como objetivo primordial "reconstruir de forma actualizada la tradición (principalmente castellana) contenida en los diccionarios bilingües y multilingües de ámbito vasco pertenecientes a los siglos XVI al XVIII". Lo realmente novedoso de este estudio es el análisis de las unidades fraseológicas como guía para la observación de los diferentes repertorios lexicográficos y la inclusión de estos en los diccionarios vascos de la época conservados en la actualidad. Cabe destacar la descripción de los repertorios bilingües catalán-español ofrecida por Cristina Gelpí en su artículo "La lexicografía entre el catalán y el castellano (XVI-XIX) y su proyección en el diccionario de Pere Labernia". En este caso, el estudio se centra fundamentalmente en los rasgos principales del Diccionari de la llengua catalana ab la correspondencia castellana y llatina (1839) de Labernia, destacando el análisis de la macroestructura y microestructura del diccionario a través de un gran muestrario de ejemplos extraídos de la obra.

Resultan interesantes dos estudios con un enfoque distinto a los anteriores: por un lado, Esther Hernández en "La lexicografía hispano-amerindia del siglo XVI" trata la convivencia del español con otras lenguas fuera de la península y, en este caso, recogiendo los rasgos más relevantes de una taxonomía específica de vocabularios creados por los misioneros lexicográficos durante el siglo XVI que ponían en paralelo al castellano con las principales lenguas en territorio americano. Por otro lado, Antonia $\mathrm{M}^{a}$ Medina Guerra en su estudio "Cinco siglos en la historia de los diccionarios bilingües latínespañol y español-latín (XV-XIX)" realiza un recorrido por la labor lexicográ- 
fica bilingüe establecida entre el castellano y el latín, siendo este último un medio de comunicación que cayó progresivamente en desuso gracias a causas como la progresiva importancia de aprender otras lenguas modernas para favorecer todo tipo de intercambios internacionales. En este artículo prima tanto el análisis específico de los diversos repertorios lexicográficos propuestos por la autora como las fuentes de los mismos, evidenciando en todo momento la importancia de predecesores en la misma labor como Nebrija $\mathrm{u}$ otros grandes diccionarios monolingües latinos o bilingües y plurilingües provenientes de la lexicografía italiana.

Por último, este monográfico se completa con el análisis de la producción lexicográfica que une al español con cuatro lenguas de gran relevancia debido a su uso extendido a nivel peninsular y también en Europa occidental: italiano, portugués, inglés y árabe. José Joaquín Martínez Egido traza en su artículo "Origen y desarrollo positivo de la lexicografía bilingüe español-italiano (siglos XVI-XIX)" una panorámica detallada de la práctica lexicográfica bilingüe que vinculó el español y el italiano durante cuatro siglos, evidenciando los rasgos más relevantes de estas obras, desde su extensión, hasta la técnica lexicográfica utilizada. Diete Messner en su breve estudio "Los diccionarios bilingües español-portugués desde el principio hasta el siglo XIX" realiza una taxonomía de carácter descriptivo de los principales diccionarios bilingües de las lenguas portuguesa y española. En este caso, la brevedad del estudio y la escasez de datos aportados con respecto a otros artículos se justifica con las siguientes palabras del autor: "[...] podemos repetir que la lexicografía bilingüe de las lenguas española y portuguesa surge muy tarde en comparación con otras diccionarísticas". Por otro lado, en "La lexicografía plurilingüe inglesa en los siglos XVI y XVII: los diccionarios de James Howell", F. Javier Sánchez Escribano estudia la producción lexicográfica de carácter plurilingüe que ponía en relación al inglés con el español, el francés y el italiano en los siglos propuestos. Además, parte de las obras Lexicon Tetraglotton y Nomenclatura de James Howell como ejemplos básicos para evidenciar los rasgos más importantes en la confección de los diccionarios de la época citada. Finalmente, Francisco Vidal Castro ofrece en "Los diccionarios españolárabe: más de cinco siglos de lexicografía bilingüe" un estudio lexicográfico tanto global (incluyendo aspectos de carácter histórico, cultural o sociolingüístico) como comparativo de los principales diccionarios castellano-árabe insertados entre los siglos XVI y XIX. En este caso, el autor se centra en las obras de cuatro autores específicos: Pedro de Alcalá, Bernardino González, Francisco Cañes, Patricio de la Torre y José Lerchundi. 
Esta recopilación de trabajos sobre lexicografía bilingüe y plurilingüe del español brinda la oportunidad de actualizar el estudio en el discurrir histórico de esta disciplina durante los siglos XV-XIX. La organización de los diversos artículos ofrece una panorámica general no sólo del castellano y su producción lexicográfica en relación a otras lenguas de progresivo uso y extensión tanto en la península como en territorio europeo, sino también de la lexicografía plurilingüe que unía multitud de lenguas en únicos volúmenes, de las obras que vinculaban el castellano con el latín o bien de las recopilaciones que relacionaban al español con las lenguas de los nuevos territorios americanos. Del mismo modo, los estudios recopilados en este monográfico ofrecen, por un lado, una visión analítica de las obras lexicográficas mediante el tratamiento particular y comparativo de ejemplos extraídos de volúmenes de los principales autores; por otro lado, la lectura de estos artículos también puede brindar al lector una panorámica histórico-cultural de la época tratada, evidenciando así las razones que han causado el incremento de la producción lexicográfica bilingüe y plurilingüe en una sociedad con una necesidad imperiosa de ampliar sus conocimientos lingüísticos en lenguas modernas. Sin duda, el monográfico cumple con los objetivos fijados de forma notable; además, es necesario destacar el gran trabajo de reunir en un único volumen una amplia cantidad de información variada y estructurada sobre la labor lexicográfica bilingüe y plurilingüe del español en los siglos XV-XIX, conformando así una herramienta de una utilidad inestimable para futuras investigaciones en esta disciplina. 